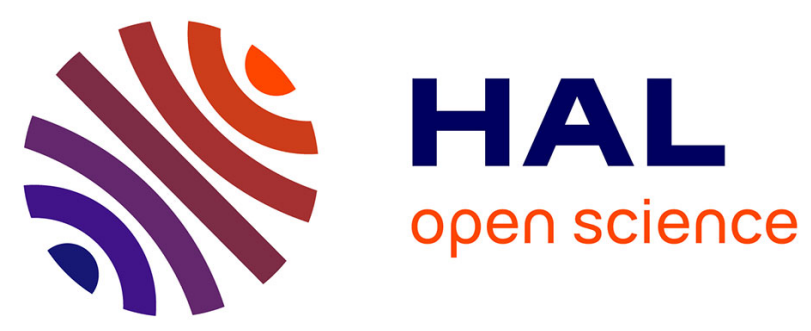

\title{
Eye Movements in Amyotrophic Lateral Sclerosis and its Mimics: A Review with Illustrative Cases
}

Colette G Donaghy, Matthew James Thurtell, Erik P Pioro, J Mark Gibson, R John Leigh

\section{- To cite this version:}

Colette G Donaghy, Matthew James Thurtell, Erik P Pioro, J Mark Gibson, R John Leigh. Eye Movements in Amyotrophic Lateral Sclerosis and its Mimics: A Review with Illustrative Cases. Journal of Neurology, Neurosurgery and Psychiatry, 2010, 82 (1), pp.110. 10.1136/jnnp.2010.212407. hal-00594144

\section{HAL Id: hal-00594144 \\ https://hal.science/hal-00594144}

Submitted on 19 May 2011

HAL is a multi-disciplinary open access archive for the deposit and dissemination of scientific research documents, whether they are published or not. The documents may come from teaching and research institutions in France or abroad, or from public or private research centers.
L'archive ouverte pluridisciplinaire HAL, est destinée au dépôt et à la diffusion de documents scientifiques de niveau recherche, publiés ou non, émanant des établissements d'enseignement et de recherche français ou étrangers, des laboratoires publics ou privés. 


\title{
Eye Movements in Amyotrophic Lateral Sclerosis and its Mimics: A Review with Illustrative Cases
}

\author{
Colette Donaghy $\mathrm{MD}^{1}$, Matthew J. Thurtell MBBS${ }^{2}$, Erik P. Pioro MD $\mathrm{PhD}^{3}$, \\ J. Mark Gibson $\mathrm{MD}^{1}$, R. John Leigh $\mathrm{MD}^{2}$ \\ ${ }^{1}$ Department of Neurology, Royal Victoria Hospital, Belfast, Northern Ireland \\ ${ }^{2}$ Department of Neurology, University Hospitals of Cleveland, and Daroff-Dell'Osso \\ Laboratory, Veterans Affairs Medical Center, Cleveland, Ohio, USA \\ ${ }^{3}$ Department of Neurology, Neurological Institute, Cleveland Clinic, Cleveland, Ohio, \\ USA
}

Keywords: Saccades, smooth pursuit; saccadic intrusions, nystagmus

Address correspondence to Colette Donaghy, Dept. of Neurology, Ward 4E, Royal Victoria Hospital, Belfast, N.Ireland BT12 6BA

Tel:00447980564685 Email: donaghy1a@hotmail.com

Total word count: 4258

Abstract word count: 89

Number of references: 40

No. figures: 2

No. tables: 1 


\section{ABSTRACT}

Abnormal eye movements are increasingly recognized in patients with amyotrophic lateral sclerosis (ALS) and, when they occur, may provide insights into the pattern and pathogenesis of the disease process. In patients with disorders that mimic ALS, abnormal eye movements may point to the correct diagnosis. In both of these circumstances, systematic examination of eye movements and interpretation of the findings with reference to modern concepts of their neural substrate will aid diagnosis and suggest pathogenesis. Here, we highlight key points with illustrative case histories and eye movement records. 


\section{INTRODUCTION}

Classical teaching is that eye movements are spared in amyotrophic lateral sclerosis (ALS), except in those patients whose lives are prolonged by artificial ventilation.[1] Over the past twenty years, however, a number of reports have indicated that patients with ALS may show a range of eye movement disorders similar to those encountered in other degenerative and hereditary neurological diseases.[2-16] These reports raise several questions. Do abnormal eye movements provide any insights into the pathogenesis of the disease process in those patients who show them? Which diagnoses should the clinician consider when confronted with an apparent "ALS patient" who has abnormal eye movements? Can eye movement abnormalities provide clues to accurate diagnosis of disorders that mimic ALS? What eye movement abnormalities are consistent with a diagnosis of ALS? Much is now known about the neurobiology of eye movements, making them widely used as diagnostic and research tools. Salient features of the properties and neural substrate of the functional classes of eye movement are summarized in Table 1 of supplementary material and Figure 1 as a background to this review; the reader is referred to current texts for more details.[17 18] We will then discuss, in turn, disorders of saccades, smooth pursuit, ocular fixation, and ophthalmoplegia in ALS. We also discuss how an advance in molecular pathology techniques, namely TAR DNA-binding protein-43 (TDP-43) staining,[19] may provide insight into a progressive supranuclear palsy (PSP) variant of ALS. Finally, we discuss how eye movements may help with accurate diagnosis of disorders that mimic ALS. Case histories are presented to illustrate these points.

\section{SACCADE ABNORMALITIES IN ALS}

A saccade is a rapid eye movement that brings the image of an object of interest onto the fovea, for clearest vision. Several types of saccade can be tested at the bedside and 
measured in the laboratory, including visually-guided saccades, memory-guided saccades, and antisaccades; we will discuss abnormalities of each of these, in turn.

\section{Disturbance of Visually-Guided (“Reflexive”) Saccades in ALS}

The peak velocity of saccades is a function of their amplitude; large saccades in humans may exceed 500 degrees/second. The pulse of innervation driving the eye muscles is generated by burst neurons in the brainstem reticular formation (Figure 1B). The paramedian pontine reticular formation (PPRF) houses burst neurons for horizontal saccades, whereas the rostral interstitial nucleus of the medial longitudinal fasciculus (riMLF) in the midbrain houses burst neurons for vertical and torsional saccades (Figure 1B). Between saccades, burst neurons are inhibited by omnipause neurons in the nucleus raphe interpositus in the pons. Prior to the onset of a saccade, omnipause neurons cease discharging, allowing the burst neurons to fire. Current views are that lesions of either the burst or omnipause neurons could cause slowed saccades.[18]

Saccades made reflexively to novel visual stimuli were thought to be normal in patients with ALS. However, Donaghy and colleagues found that reflexive saccades were slower in bulbar-onset compared with spinal-onset ALS.[5] A number of older studies have also reported slow saccades. Leveille et al described slow reflexive saccades in two of ten ALS patients with rapidly-progressive disease.[14] Similarly, Ohki et al found that four of nine ALS patients showed slower reflexive saccades compared with age-matched controls.[9] It is therefore likely that slow saccades in ALS patients are indicative of brainstem pathology.

\section{Is there a Progressive Supranuclear Palsy (PSP) Variant of ALS?}

Supranuclear gaze palsies with slow saccades have been reported in ALS patients, often in association with cognitive impairment or bulbar-onset disease. [3 1013 15] 


\section{Averbuch-Heller and colleagues reported slow vertical saccades in two ALS patients} with bulbar symptoms; post mortem examination in one demonstrated neuronal cell loss in the riMLF and substantia nigra, with relative preservation of the ocular motor nuclei.[3] We recently studied a similar patient, as described in the text box.

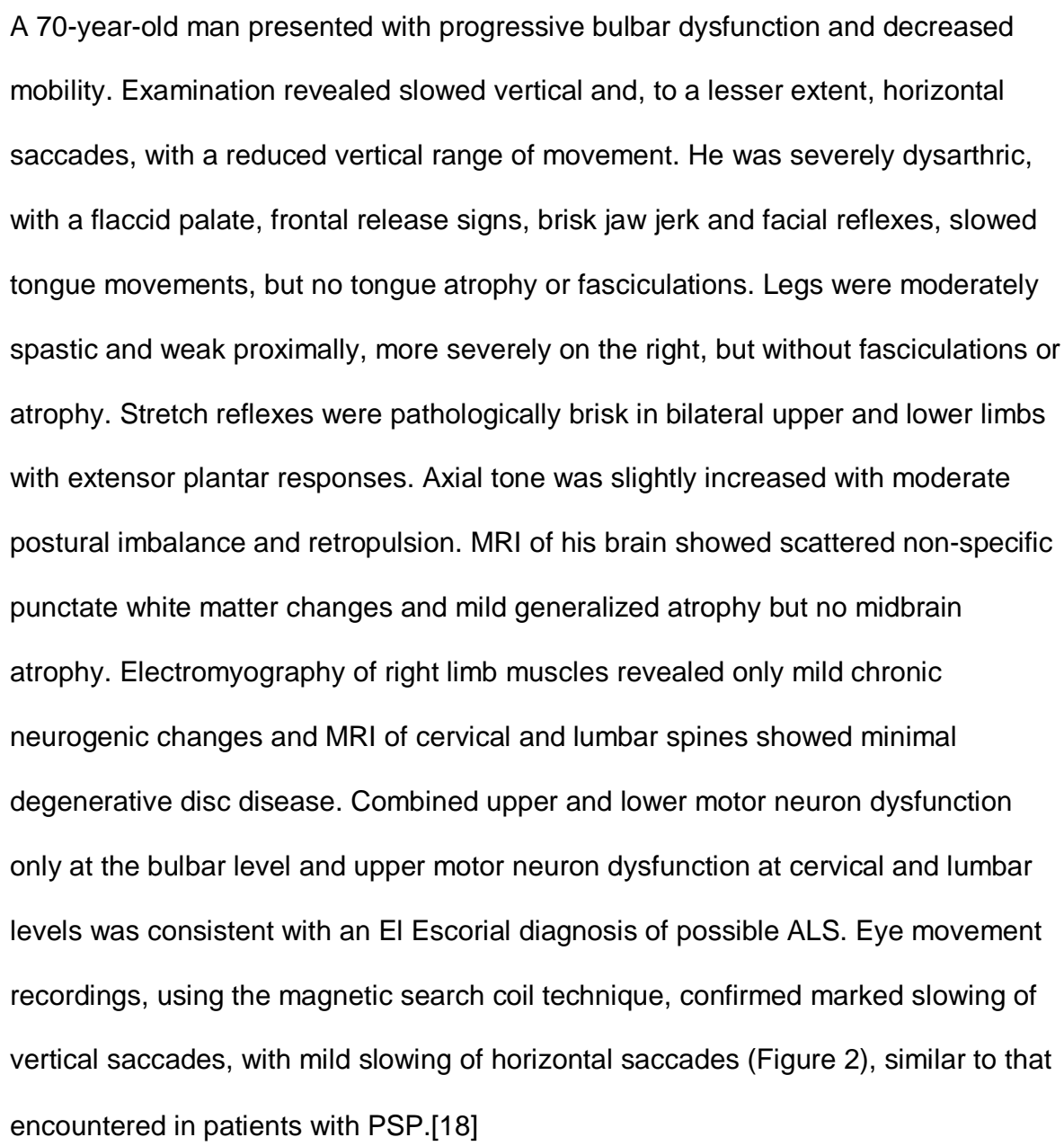

A recent neuropathological study of a patient with an ALS-Plus syndrome resembling PSP found TDP-43 positive inclusions in a pattern consistent with ALS.[20] The authors described a 66-year-old man with progressive bulbar palsy and limb weakness. He demonstrated extrapyramidal signs, as well as slow vertical and horizontal saccades 
with supranuclear gaze palsy. Neuropathological findings included corticospinal tract degeneration and loss of anterior horn motor neurons. TDP-43 positive inclusions were found in anterior horn cells, motor cortex, midbrain, hypoglossal nucleus, globus pallidus, caudate, putamen, hippocampus, and substantia nigra. Although the inclusions were found in the midbrain, the authors did not mention involvement of the riMLF.

PSP is known to be a tauopathy, and is defined pathologically by an accumulation of tau protein and neuropil threads in the pallidum, subthalamic nucleus, red nucleus, substantia nigra, pontine tegmentum, striatum, oculomotor nucleus, medulla, and dentate nucleus.[21] Although not proven, it is likely that the supranuclear vertical gaze palsy of PSP arises due to involvement of burst neurons in the riMLF.[18] TDP-43 has recently been found to be a major component of the ubiquinated inclusions characteristic of frontotemporal lobar dementia (FTLD) and sporadic ALS,[19] and so one might ask why, with such differing pathologies, there are clinical similarities in the ocular motor phenotypes of PSP and ALS? Firstly, neurodegenerative disorders associated with extrapyramidal disease can be seen in association with both tau and alpha-synuclein pathology, highlighting that one phenotype does not necessarily indicate a particular pathology. Secondly, with the discovery of TDP-43 as the major disease protein in ALS, we now have a clearer idea about the extent of pathology in ALS. In a neuropathological study of TDP-43 in 31 ALS patients, Geser et al found that the basal ganglia and substantia nigra were the regions most frequently involved outside of the motor system; the midbrain and pons, which house the burst neurons for saccades, are also involved in about $50 \%$ of cases.[22]

We propose that slow saccades can be part of the clinical profile of bulbar-onset ALS and that they indicate involvement of the brainstem reticular formation that houses the neural machinery for generating saccades (Figure 1B). In a proportion of such cases, the pathology may be extensive enough to produce supranuclear gaze palsy, with or 
without extrapyramidal features, thus presenting as a PSP-variant of ALS. Unpublished work by one of the authors (CD) comparing eye movements in 8 patients with PSP and 14 patients with bulbar-onset ALS found that there were many similarities, with both having slowed reflexive saccades and an increased frequency of saccadic intrusions (SIs) during attempted fixation, although the abnormalities were more marked in the PSP group. Clinicians should therefore be aware of the potential for misdiagnosis due to overlap between the clinical and eye movement abnormalities in these conditions.

\section{Disturbance of Volitional Saccades in ALS}

Although the clinical examination of eye movements may be normal in ALS, laboratory evaluation of the cognitive control of saccades, especially testing of memory-guided saccades and antisaccades, has provided important insights. Memory-guided saccades are made towards a visual target that has been flashed at a peripheral location some time (typically several seconds) previously. Antisaccades are made to the imagined mirror image of a visually-presented target; for example, when a target is flashed at a location 10 degrees to the left of centre, the subject is required to generate a saccade to an imagined location 10 degrees to the right of centre. Both "short-term" memory-guided saccades (where the remembered target was shown seconds before) and antisaccades are abnormal in ALS patients. ALS patients make accurate memory-guided saccades, but with increased latency (reaction time).[12] In the antisaccade task, ALS patients generate saccades that are both inaccurate and made at increased latency.[5 12] One study separated antisaccade errors into type 1 (subject looks incorrectly towards the target and does not self-correct) and type 2 (subject looks incorrectly towards the target, but self-corrects), and found that only type 1 errors were increased in ALS patients.[5] Furthermore, a positive correlation was found between type 1 errors and both the Stroop test (a neuropsychological test of attention and frontal lobe function) and the ALSFRSr 
(amyotrophic lateral sclerosis functional rating scale revised), including its bulbar subscore.

Thus, ALS patients have increased errors during the antisaccade task, as well as increased latency of antisaccades and "short-term" memory-guided saccades. How can these findings be explained? Both the frontal eye fields (FEF) and dorsolateral prefrontal cortex (DLPC), shown in Figure 1A, contribute to the programming of antisaccades, but in different ways. On one hand, the right hemisphere DLPC is activated during antisaccades,[23] and patients with DLPC lesions have an increased percentage of errors in the antisaccade task.[18] On the other hand, patients with FEF lesions have a normal percentage of errors on the antisaccade task, but make their antisaccades at increased latency. Overall, it appears that the increased antisaccade type 1 errors and latencies encountered in ALS are due to involvement of both DLPC and FEF. It is also possible to propose a hypothesis to account for generation of memory-guided saccades, since functional imaging studies suggest that DLPC contributes to spatial memory for up to about 20 seconds.[18] In summary, abnormalities in the cognitive control of saccades in ALS patients indicate frontal lobe involvement, which fits well with the ever enlarging literature from neuroimaging and neuropsychological studies of frontal lobe impairment in patients with ALS, even in those without clinical evidence of dementia.[24-26] Based on neuropsychological studies, up to $50 \%$ of non-demented ALS patients have frontal lobe impairment,[26] although these studies come from ALS-clinic-based populations and may be biased. Traditionally, it had been thought that $3-5 \%$ of ALS patients have an associated FTLD,[27] although recent evidence suggests a clinicopathological disease spectrum with overlap between ALS and FTLD.[28] 


\section{SMOOTH PURSUIT ABNORMALITIES IN ALS}

Smooth pursuit eye movements evolved to permit foveation of moving targets. It is possible to measure both the onset and maintenance of smooth pursuit. The onset of smooth pursuit is usually measured using step-ramp stimuli, in which the target steps to one side and then moves smoothly in the opposite direction. Step-ramp stimuli aim to position the image of the moving target close to the fovea of the retina at the time when the eye first starts to move; thus, they allow for the reaction time to onset of smooth pursuit and promote generation of smooth pursuit without superimposed saccades. Maintenance of smooth pursuit is often studied using small visual targets that move in predictable triangular or sinusoidal waveforms. The maintenance of smooth pursuit is usually expressed as velocity gain, the ratio of pursuit eye velocity to stimulus velocity. $A$ more indirect method to assess pursuit gain is to look for catch-up saccades, which are generated to place the fovea back on target if pursuit is inadequate.

Using a predictable, triangular stimulus waveform, Donaghy and colleagues found a reduced velocity gain in 44 ALS patients compared to controls, as well as a reduced proportion of time spent in smooth pursuit.[5] An example of impaired smooth pursuit is shown in Figure 1B of the supplementary material. Three further studies using triangular and sinusoidal waveforms also found reduced velocity gain in ALS patients compared with controls.[2 8 14] A further study found that smooth pursuit was impaired and largely replaced by catch-up saccades in 11 out of 18 ALS patients.[16] In contrast, Shaunak and colleagues assessed 17 ALS patients with a triangular waveform stimulus and found that pursuit velocity gain was normal.[12] However, Gizzi and colleagues found reduced smooth pursuit velocity gain only in ALS patients with parkinsonian features, and concluded that pursuit was normal in classical sporadic ALS.[7] Thus, most, but not all, studies have reported abnormalities of smooth pursuit gain in ALS patients. How can these findings be explained? 
Smooth pursuit is controlled by cerebro-ponto-cerebellar pathways; the cortical areas involved include parts of the temporal and parietal lobes, as well as the FEF. Posterior cortical areas involved in smooth pursuit project to the cerebellum via the dorsolateral pontine nuclei (DLPN), whereas the FEF projects via nucleus reticularis tegmenti pontis (NRTP). Neurons from the dorsal vermis and flocculus/paraflocculus of the cerebellum are thought to project to the ocular motor nuclei of the brainstem via the cerebellar fastigial nuclei, vestibular nuclei, and y-group nuclei of the brainstem.[18] Smooth pursuit gain is reduced in normal elderly subjects, as well as in patients with parkinsonian disorders, FTLD, Alzheimer's disease, cerebellar disorders, and metabolic disturbances, such as hepatic encephalopathy.[18] Impaired smooth pursuit is also due to certain medication or drug intoxications, and is therefore not diagnostically specific.[18] Nonetheless, electrophysiological and microstimulation studies of the pursuit region of the FEF indicate a role for the FEF in the setting of gain.[18] Thus, reduced smooth pursuit velocity gain in ALS patients could arise from involvement of the frontal lobes and, more specifically, the FEF.

\section{OCULAR FIXATION ABNORMALITIES IN ALS}

\section{Saccadic Intrusions}

Saccadic intrusions (SIs) consist of involuntary saccades that disrupt fixation. Sls are evident on clinical examination, especially during ophthalmoscopy. Measurements have demonstrated several types of SI, including square-wave jerks, single saccadic pulses, double saccadic pulses, and monophasic and biphasic square-wave jerks, which are most common.[18] Examples of Sls are shown in Figure 1A of the supplementary material. Sls can occur in normal subjects. However, saccadic oscillations without an intersaccadic interval, such as flutter and opsoclonus, do not occur in healthy subjects.[18] 
Palmowski et al first described fixation abnormalities in seven of eight ALS patients.[11] Shaunak and colleagues noted an increased frequency of square-wave jerks in ALS patients compared to controls, but they did not measure other SIs.[12] Donaghy and colleagues formally examined fixation in ALS and not only demonstrated an increased SI amplitude in ALS patients compared to controls, but also showed a correlation between SI amplitude, verbal fluency, and Stroop test scores (measures sensitive to frontal lobe dysfunction).[4] Thus, fixation abnormalities may be due, at least in part, to impairment of the frontal lobes or their projections to the superior colliculus.

The neural substrate of fixation comprises both cortical and brainstem components. In monkey, numerous studies have demonstrated that FEF is important for suppressing saccades, as well as initiating them.[18] Functional imaging studies suggest that the frontal lobes have a role in sustaining steady fixation in humans, with a positron emission tomography study finding activation clusters in the FEF and intraparietal sulci bilaterally when subjects fixated on a central target, but not when they simply kept their eyes open in darkness.[29] In the brainstem, electrophysiological and pharmacological inactivation studies in monkey suggest that the rostral pole of the superior colliculus is important in sustaining steady fixation.[18] The superior colliculus receives inputs from cortical areas concerned with eye movements; projections from the FEF are both direct and via the basal ganglia. Other inputs are from the mesencephalic reticular formation and cerebellar fastigial nucleus.[18] In one monkey, irrepressible saccades resulted from an infarct involving the rostral pole of the superior colliculus, adjacent reticular formation, and periaqueductal gray.[18] Pharmacological inactivation of the mesencephalic reticular formation has produced square-wave jerks in monkeys. Similarly, pharmacological inactivation of the rostral pole of the superior colliculus in a monkey reduced suppression of saccades.[18] Square-wave jerks are prominent in PSP and pallidotomy has been found to increase square wave-jerks in patients with Parkinson's disease,[18] suggesting 
a role for the basal ganglia in producing Sls. Square-wave jerks have also been reported in cerebellar disorders, such as in some spinocerebellar ataxias.[18]

In summary, the most consistent abnormality of fixation in ALS is increased SI amplitude.[5] Sls show the same relationship between amplitude, peak velocity, and duration as do voluntary saccades, and are therefore thought to be generated by the same brainstem machinery. While increases in SI amplitude could arise due to dysfunction within these pathways, correlations between SI amplitude and measures of frontal lobe dysfunction suggest that Sls could arise due to involvement of frontalcollicular pathways.

\section{Nystagmus}

A second cause for disruption of steady fixation is nystagmus, which is a repetitive toand-fro movement of the eyes that is initiated by a slow phase. It occurs when there is a disturbance within any of the mechanisms that have evolved to hold gaze steady (see Supplementary Table 1).[18] One such mechanism is the vestibulo-ocular reflex, which generates eye movements that compensate for head movements, and another is the gaze-holding mechanism, which holds the eyes in an eccentric position against the elastic restoring forces of the orbital tissues and depends on a neural network (the "neural integrator") within the brainstem and cerebellum. Lastly, pathology affecting the afferent visual system, from the eye to posterior cortex and its pontine-cerebellar projections, can also cause nystagmus. In this case, nystagmus can result from an impaired ability to correct for retinal image drift or disruption of the visual inputs that allow eye movement calibration according to visual demands. Nystagmus is rarely reported in ALS, although there are two reported cases of ALS, confirmed post-mortem, with nystagmus.[30] One of these had gaze-evoked nystagmus, followed later by supranuclear palsy of horizontal gaze and upgaze, while the other had gaze-evoked 
nystagmus with a normal range of eye movements. Gaze-evoked nystagmus often occurs with brainstem or cerebellar disease,[18] although the ensuing supranuclear gaze paresis in the first patient suggests involvement of the midbrain and pons. Post mortem examination in one of the patients revealed two small carcinoid tumours in the terminal ileum, raising the question of whether the nystagmus could have been a feature of a paraneoplastic syndrome rather than the patient's ALS.

Thakore and colleagues described three patients with downbeat nystagmus (Figure 1A, supplementary material) and a predominantly lower motor neuron syndrome, with wrist and finger extensor weakness and evidence of anterior horn cell disease.[31] Cerebellar atrophy was noted on imaging in one patient, who had initially presented with balance and gait difficulties. It is possible that these patients had a distinct syndrome, although their electrophysiology was consistent with ALS. In summary, nystagmus is not a common finding in ALS; when it occurs, it may present an opportunity to investigate the pathophysiology of the disorder, but could also suggest an ALS mimic (discussed in the last section).

\section{OPHTHALMOPLEGIA}

Case reports of ALS patients with external ophthalmoplegia are uncommon, and mainly concern patients whose life has been prolonged by long-term ventilation.[1] In some reports, involvement of the ocular motor nuclei has been noted on post mortem examination.[32] Kaminski and colleagues reviewed the evidence for sparing of ocular motor neurons in ALS.[51] When comparing ocular motor with spinal motor neurons, there are differences in glutamate neurotransmitter activity, calcium-binding protein, androgen receptor expression, and their dependence on trophic factors. However, no single theory satisfactorily explains why ocular motor neurons are relatively spared in

ALS. It is possible that patients who develop external ophthalmoplegia represent the 
extreme end of the disease spectrum, where the process has extended to involve the ocular motor nuclei of the brainstem.

\section{SUMMARY OF EYE MOVEMENT ABNORMALITIES IN ALS}

Much like the continuum of cognitive disturbance proposed in the ALS literature,[28] eye movement abnormalities probably form a spectrum, with normal eye movements at one end of the spectrum and supranuclear gaze palsies and, rarely, ophthalmoplegia at the other. Many patients with sporadic ALS have increased latency of antisaccades, with increased antisaccade errors, reduced smooth pursuit velocity gain, and increased saccadic intrusion amplitude. Current evidence suggests that these abnormalities arise due to frontal lobe involvement. In those patients with advanced or bulbar-onset disease, however, it is likely that more extensive pathological changes in the brainstem give rise to slowed saccades with or without supranuclear gaze palsy. In these instances, ocular motor abnormalities may mimic those of PSP, with more marked involvement of vertical saccades and relative sparing of horizontal saccades. Many of these ALS patients have other ocular motor signs suggestive of PSP, such as SI, increased antisaccade errors, and decreased smooth pursuit gain.[5 8 12 14] Nonetheless, with the advent of sensitive molecular pathological markers, such as TDP-43, future clinicopathological studies are likely to identify the neural substrate of atypical eye movement and clinical findings in ALS and, in doing so, further our understanding of the clinical spectrum of this disorder.

\section{EYE MOVEMENT ABNORMALITIES IN ALS MIMICS}

The syndromes that most commonly mimic ALS - benign fasciculation syndrome, cervical spondylitic myelopathy, multifocal motor neuropathy, and inclusion body myositis - are not known to cause eye movement abnormalities. However, a range of other motor neuron disorders can produce an ALS-like picture, with associated eye 
movement abnormalities (Table 1). Palsies of the oculomotor (III), trochlear (IV), and abducens $(\mathrm{VI})$ cranial nerves $(\mathrm{CN})$ should suggest disease in the subarachnoid space, cavernous sinuses, orbit, or posterior nasopharynx. Rare hereditary progressive bulbar syndromes, such as Brown-Vialetto-Van Laere [33] and Fazio-Londe [34] syndromes, can also produce CN III, IV, and VI palsies. Although hearing loss is suggestive of these syndromes, it is unknown if vestibular dysfunction occurs in affected patients.

Parkinsonian syndromes, especially PSP, may present like ALS, with prominent bulbar dysfunction and decreased mobility. PSP patients are known to have a distinctive eye movement disorder: slowing of vertical saccades, along with increased frequency of saccadic intrusions (square wave jerks).[18] However, the potential for diagnostic difficulty exists when taking into consideration the case reports describing slow saccades with or without supranuclear gaze palsy in ALS patients with or without a bulbar onset.[3 $101315]$

Kennedy's disease (KD), also known as spinal-bulbar muscular atrophy, is an Xlinked degenerative condition of lower motor neurons causing late-onset muscular atrophy, with fasciculations of the face and tongue. KD can mimic ALS, but differs from sporadic ALS with absence of pyramidal involvement and a slowly-progressive course. Unpublished work by one of the authors (CD) has found normal fixation, saccades, and smooth pursuit in four patients with KD. Reflexive saccades, however, were found to be slowed in one KD patient we have studied (Figure 2 supplementary material).[35]

Bulbar myasthenia gravis (MG) can occasionally be mistaken for ALS. MG can present with fluctuating ptosis, reduced range of eye movements that does not conform to specific ocular motor nerves, or even complete ophthalmoplegia. Finding a reduced range of eye movement with preservation of small, fast saccades ("quiver movements") is highly suggestive of MG.[18] Although rare, late-onset Tay-Sach's disease (LOTS), a lysosomal storage disorder due to inactivity of the enzyme hexosaminidase A, can also 
mimic ALS, but typically gives rise to interrupted or multi-step saccades, which have not been reported to occur in ALS.[18] The spinocerebellar ataxias (SCAs) are a constantly enlarging group of inherited multi-system disorders that can present with cerebellar, pyramidal, and extrapyramidal dysfunction. SCA-3 (Machado-Joseph disease) can present with an ALS-like picture and therefore should be considered in the differential diagnosis of ALS. While approximately $56 \%$ of SCA-3 patients have ophthalmoplegia, other ocular motor findings, such as saccadic hypermetria and gaze-evoked nystagmus, are suggestive of cerebellar disease.[36] SCA-3 is also known to cause reduced gain of the vestibulo-ocular reflex.[18]

\section{CONCLUSIONS}

We can now challenge the widely held view that eye movements are normal in ALS. As we have shown, a range of eye movement abnormalities can occur in ALS and have provided insights into the distribution and nature of the disease process. Eye movements have the potential to help identify ALS mimics in patients who are misdiagnosed due to the inherent difficulty in diagnosing ALS. Eye movements, which are easy to record and for which a neural substrate is well established, provide us with a powerful behavioral tool to investigate the workings of the brain in ALS. Measurement of eye movement abnormalities in future longitudinal studies seems likely to provide further insights into the nature of this stubborn and malign disease. 


\section{ACKNOWLEDGEMENTS}

Supported by NIH grant EY06717, Department of Veterans Affairs, and Evenor Armington Fund (Dr. Leigh). The funding sources had no role in the writing of this review.

\section{COPYRIGHT}

The Corresponding Author has the right to grant on behalf of all authors and does grant on behalf of all authors, an exclusive licence (or non-exclusive for government employees) on a worldwide basis to the BMJ Group and co-owners or contracting owning societies (where pusblished by the BMJ Group on their behalf), and its Licensees to permit this article (if accepted) to be published in the Journal of Neurology, Neurosurgery and Psychiatry and any other BMJ Group products and to exploit all subsidiary rights, as set out in our licence (http://jnnp .bmjjournals.com/ifora/licence.pdf).

\section{CONFLICTS OF INTEREST}

The authors declare no conflicts of interest.

\section{AUTHORS CONTRIBUTIONS}

All authors were involved in writing the manuscript. In addition, Colette Donaghy performed the literature search, Matthew Thurtell and John Leigh recorded eye movements for the patients highlighted in the case reports and assembled the figures, and Erik Pioro identified patients for the case studies. 
Table 1: ALS and its mimics, categorised according to eye movement findings

\begin{tabular}{|c|c|}
\hline Eye movement findings & ALS or its mimic \\
\hline No known abnormality & $\begin{array}{l}\text { Benign fasciculation syndrome } \\
\text { Cervical Spondylitic Myelopathy } \\
\text { Hyperparathyroidism } \\
\text { Inclusion Body Myositis } \\
\text { Multifocal Motor Neuropathy }\end{array}$ \\
\hline $\begin{array}{l}\text { Ocular misalignment and } \\
\text { limited range of movement }\end{array}$ & $\begin{array}{l}\text { 1. Cranial Nerve Palsies: } \\
\text { Skull base and posterior nasopharyngeal } \\
\text { lesions, Sjogren's syndrome [18], Fazio- } \\
\text { Londe [34], Brown-Vialetto-Van Leare } \\
\text { syndrome [33], Polio [37] } \\
\text { 2. Neuromuscular junction disease: MG } \\
\text { 3. Restrictive Ophthalmopathy: } \\
\text { Thyroid-associated (Graves') orbitopathy } \\
\text { /Hyperthyroidism } \\
\text { 4. Ophthalmoplegia: SCA 3 (Machado- } \\
\text { Joseph Disease) [36] } \\
\text { 5. Unspecified restricted vertical and } \\
\text { horizontal ocular motility: Lead [38] } \\
\text { 6. Chronic progressive external } \\
\text { ophthalmoplegia due to mitochondrial } \\
\text { myopathy [18] }\end{array}$ \\
\hline $\begin{array}{l}\text { Vestibular-Ocular Reflex: } \\
\text { Reduced Gain }\end{array}$ & $\begin{array}{l}\text { SCA-3 (Machado-Joseph Disease) [18] } \\
\text { Guamanian ALS [39] }\end{array}$ \\
\hline $\begin{array}{l}\text { Ocular fixation: } \\
\text { 1. Saccadic Intrusions } \\
\text { A) Increased frequency } \\
\text { B) Increased amplitude } \\
\text { 2. Unspecified nystagmus }\end{array}$ & $\begin{array}{l}\text { PSP, MSA [18] } \\
\text { ALS [4], PSP [18] } \\
\text { Polio [37] }\end{array}$ \\
\hline
\end{tabular}




\begin{tabular}{|c|c|}
\hline $\begin{array}{l}\text { 3. Downbeat nystagmus } \\
\text { 4. Periodic alternating and } \\
\text { centripetal nystagmus }\end{array}$ & $\begin{array}{l}\text { MSA [18] } \\
\text { CJD [18] }\end{array}$ \\
\hline \multicolumn{2}{|l|}{ Saccades: } \\
\hline 1. Slow reflexive saccades & $\begin{array}{l}\text { MSA [18], CJD* [18], ALS [5], } \\
\text { Kennedy’s Disease [35] }\end{array}$ \\
\hline 2. Increased antisaccade errors & $\begin{array}{l}\text { ALS [5 } 6 \text { 12], PSP [18] } \\
\text { Frontal lobe pathology co-existent with } \\
\text { cervical/lumbar root disease }\end{array}$ \\
\hline 3. Increased antisaccade latency & $\begin{array}{l}\text { Frontal lobe pathology co-existent with } \\
\text { cervical/lumbar root disease }\end{array}$ \\
\hline 4. Increased latency of & ALS [6 12] \\
\hline remembered saccades & ALS [5 9 14], PSP* [18] \\
\hline $\begin{array}{l}\text { 5. Increased reflexive saccade } \\
\text { latency }\end{array}$ & PSP [18] \\
\hline \multicolumn{2}{|l|}{ Saccadic dysmetria: } \\
\hline 1. Hypometria & PSP, MSA, MG \\
\hline $\begin{array}{l}\text { 2. Hypometria due to premature } \\
\text { termination }\end{array}$ & LOTS [18] \\
\hline 3. Hypermetria & SCA-3 (Machado-Joseph Disease) [18] \\
\hline 4. Hyperfast, dysmetria & MG [18] \\
\hline \multicolumn{2}{|l|}{ Smooth Pursuit: } \\
\hline 1. Reduced velocity gain & ALS [2 5 8], PSP [18] \\
\hline 2. Broken by saccades & ALS [16], HSP (SPG30 mutation) [40] \\
\hline Multi-system & $\begin{array}{l}\text { HIV infection [18] } \\
\text { Guamanian ALS [39] }\end{array}$ \\
\hline
\end{tabular}

*Most particularly noted in vertical saccades

LOTS, Late-Onset Tay-Sach's disease; PSP, Progressive Supranuclear Palsy; MSA, Multiple System Atrophy; CBGD, Corticobasal Ganglionic Degeneration; SCA, Spinocerebellar Ataxia; MG, Myasthenia Gravis; CJD, Creutzfeldt-Jakob Disease; HSP, Hereditary Spastic Paraplegia. 


\section{FIGURE LEGEND:}

Figure 1: (A) Probable location of cortical areas important for eye movements in human brain. MST: medial superior temporal visual area; MT: middle temporal visual area (in humans, may form a contiguous area with MST). See text for discussion. Adapted from

Leigh and Zee (2006). (B) A sagittal section of the monkey brainstem showing structures important in the control of vertical and horizontal gaze. Excitatory burst neurons (EBN) for vertical saccades lie in the rostral interstitial nucleus of the medial longitudinal fasciculus (riMLF). The interstitial nucleus of Cajal (INC) contributes to vertical gaze holding and also houses some inhibitory burst neurons (IBN) for vertical saccades. The shaded areas indicate the paramedian pontine reticular formation (PPRF), which houses EBN for horizontal saccades, and medullary reticular formation (Med RF), which houses (IBN) for horizontal saccades. The asterisk indicates the location of omnipause neurons. III: oculomotor nucleus; IV: trochlear nucleus; VI: abducens nucleus; CG: central gray; h: habenular complex; mb: mammillary body; CN III: rootlets of the oculomotor nerve; N IV: trochlear nerve; CN VI: rootlets of the abducens nerve; CN VII: genu of the facial nerve; MRF: mesencephalic reticular formation; NPH: nucleus prepositus hypoglossi; ND: nucleus of Darkschewitsch; NRTP: nucleus reticularis tegmenti pontis; PC: posterior commissure; TR: tractus retroflexus. The arrow refers to the Horsley-Clarke plane of section. Courtesy of Jean Buttner-Ennever.

Figure 2: Saccadic abnormalities in a 70-year-old man with bulbar-onset ALS. Eye movement recordings using the magnetic search coil technique revealed slowing and reduced amplitude of vertical saccades. Horizontal saccades were also mildly slowed, with saccades of the adducting eye being slower than those of the abducting eye, giving the appearance of bilateral internuclear ophthalmoplegia. Shaded zones indicate the $95 \%$ prediction intervals for a group of normal control subjects, with the white line indicating the mean. 


\section{REFERENCES}

1. Mizutani T, Aki M, Shiozawa R, et al. Development of ophthalmoplegia in amyotrophic lateral sclerosis during long-term use of respirators. J Neurol Sci 1990;99(23):311-9.

2. Abel LA, Williams IM, Gibson KL, et al. Effects of stimulus velocity and acceleration on smooth pursuit in motor neuron disease. J Neurol 1995;242(7):419-24.

3. Averbuch-Heller L, Helmchen C, Horn AK, et al. Slow vertical saccades in motor neuron disease: correlation of structure and function. Ann Neurol 1998;44(4):641-8.

4. Donaghy C PR, Abrahams S, Cardwell C, Hardiman O, Patterson V, McGivern RC, Gibson JM. Ocular fixation instabilities in Motor Neurone Disease: a marker of frontal lobe dysfunction? Journal of Neurology 2009;256(3):420-26.

5. Donaghy C PR, Abrahams S, Cardwell C, Hardiman O, Patterson V, McGivern RC, Gibson JM. Slow saccades in bulbar-onset Motor Neurone Disease. Journal of Neurology 2010;257(7):1134-40.

6. Evdokimidis I, Constantinidis TS, Gourtzelidis P, et al. Frontal lobe dysfunction in amyotrophic lateral sclerosis. J Neurol Sci 2002;195(1):25-33.

7. Gizzi M, DiRocco A, Sivak M, et al. Ocular motor function in motor neuron disease. Neurology 1992;42(5):1037-46.

8. Marti-Fabregas J, Roig C. Oculomotor abnormalities in motor neuron disease. J Neurol 1993;240(8):475-8.

9. Ohki M, Kanayama R, Nakamura T, et al. Ocular abnormalities in amyotrophic lateral sclerosis. Acta Otolaryngol Suppl 1994;511:138-42.

10. Okuda B, Yamamoto T, Yamasaki M, et al. Motor neuron disease with slow eye movements and vertical gaze palsy. Acta Neurol Scand 1992;85(1):71-6. 
11. Palmowski A, Jost WH, Prudlo J, et al. Eye movement in amyotrophic lateral sclerosis: a longitudinal study. Ger J Ophthalmol 1995;4(6):355-62.

12. Shaunak S, Orrell RW, O'Sullivan E, et al. Oculomotor function in amyotrophic lateral sclerosis: evidence for frontal impairment. Ann Neurol 1995;38(1):38-44.

13. Ushio M, Iwasaki S, Sugasawa K, et al. Atypical motor neuron disease with supranuclear vertical gaze palsy and slow saccades. Auris Nasus Larynx 2009;36(1):85-7.

14. Leveille A, Kiernan J, Goodwin JA, et al. Eye movements in amyotrophic lateral sclerosis. Arch Neurol 1982;39(11):684-6.

15. Kobayashi M, Ikeda K, Kinoshita M, et al. Amyotrophic lateral sclerosis with supranuclear ophthalmoplegia and rigidity. Neurol Res 1999;21(7):661-4.

16. Jacobs L, Bozian D, Heffner RR, Jr., et al. An eye movement disorder in amyotrophic lateral sclerosis. Neurology 1981;31(10):1282-7.

17. Kennard CL, RJ., editor. Using Eye Movements as an Experimental Probe of Brain Function. Progress in Brain Research Amsterdam: Elsevier, 2008.

18. Leigh RJ, Zee DS. The neurology of eye movements. 4th edition ed. New York: Oxford University Press, 2006.

19. Arai T, Hasegawa M, Akiyama $\mathrm{H}$, et al. TDP-43 is a component of ubiquitin-positive tau-negative inclusions in frontotemporal lobar degeneration and amyotrophic lateral sclerosis. Biochem Biophys Res Commun 2006;351(3):602-11.

20. McCluskey LF, Elman LB, Martinez-Lage M, et al. Amyotrophic lateral sclerosis-plus syndrome with TAR DNA-binding protein-43 pathology. Arch Neurol 2009;66(1):121-4.

21. Williams DR, Lees AJ. Progressive supranuclear palsy: clinicopathological concepts and diagnostic challenges. Lancet Neurol 2009;8(3):270-9. 
22. Geser F, Brandmeir NJ, Kwong LK, et al. Evidence of multisystem disorder in wholebrain map of pathological TDP-43 in amyotrophic lateral sclerosis. Arch Neurol 2008;65(5):636-41.

23. Ford KA, Goltz HC, Brown MR, et al. Neural processes associated with antisaccade task performance investigated with event-related FMRI. J Neurophysiol 2005;94(1):429-40.

24. Abrahams S, Goldstein LH, Kew JJ, et al. Frontal lobe dysfunction in amyotrophic lateral sclerosis. A PET study. Brain 1996;119 ( Pt 6):2105-20.

25. Kew JJ, Goldstein LH, Leigh PN, et al. The relationship between abnormalities of cognitive function and cerebral activation in amyotrophic lateral sclerosis. A neuropsychological and positron emission tomography study. Brain 1993;116 ( Pt 6):1399-423.

26. Ringholz GM, Appel SH, Bradshaw M, et al. Prevalence and patterns of cognitive impairment in sporadic ALS. Neurology 2005;65(4):586-90.

27. Neary D, Snowden JS, Mann DM. Cognitive change in motor neurone disease/amyotrophic lateral sclerosis (MND/ALS). J Neurol Sci 2000;180(1-2):1520.

28. Geser F, Lee VM, Trojanowski JQ. Amyotrophic lateral sclerosis and frontotemporal lobar degeneration: a spectrum of TDP-43 proteinopathies. Neuropathology;30(2):103-12.

29. Petit L, Dubois S, Tzourio N, et al. PET study of the human foveal fixation system. Hum Brain Mapp 1999;8(1):28-43.

30. Kushner MJ, Parrish M, Burke A, et al. Nystagmus in motor neuron disease: clinicopathological study of two cases. Ann Neurol 1984;16(1):71-7. 
31. Thakore NJ, Pioro EP, Rucker JC, et al. Motor neuronopathy with dropped hands and downbeat nystagmus: a distinctive disorder? A case report. BMC Neurol 2006;6:3.

32. Harvey DG, Torack RM, Rosenbaum HE. Amyotrophic lateral sclerosis with ophthalmoplegia. A clinicopathologic study. Arch Neurol 1979;36(10):615-7.

33. Sathasivam S. Brown-Vialetto-Van Laere syndrome. Orphanet J Rare Dis 2008;3:9.

34. Gulati T, Dewan V, Kumar P, et al. Progressive bulbur paralysis (Fazio-Londe disease). Indian J Pediatr 2004;71(1):101-2.

35. Thurtell MJ, Pioro EP, Leigh RJ. Abnormal eye movements in Kennedy disease. Neurology 2009;72(17):1528-30.

36. Riess O, Rub U, Pastore A, et al. SCA3: neurological features, pathogenesis and animal models. Cerebellum 2008;7(2):125-37.

37. Murray RG, Walsh FB. Ocular abnormalities in poliomyelitis and their pathogenesis. Can Med Assoc J 1954;70(2):141-7.

38. Sanz P, Nogue S, Vilchez D, et al. Progressive supranuclear palsy-like parkinsonism resulting from occupational exposure to lead sulphate batteries. $J$ Int Med Res 2007;35(1):159-63.

39. Lepore FE, Steele JC, Cox TA, et al. Supranuclear disturbances of ocular motility in Lytico-Bodig. Neurology 1988;38(12):1849-53.

40. Klebe S, Azzedine H, Durr A, et al. Autosomal recessive spastic paraplegia (SPG30) with mild ataxia and sensory neuropathy maps to chromosome $2 q 37.3$. Brain 2006;129(Pt 6):1456-62. 


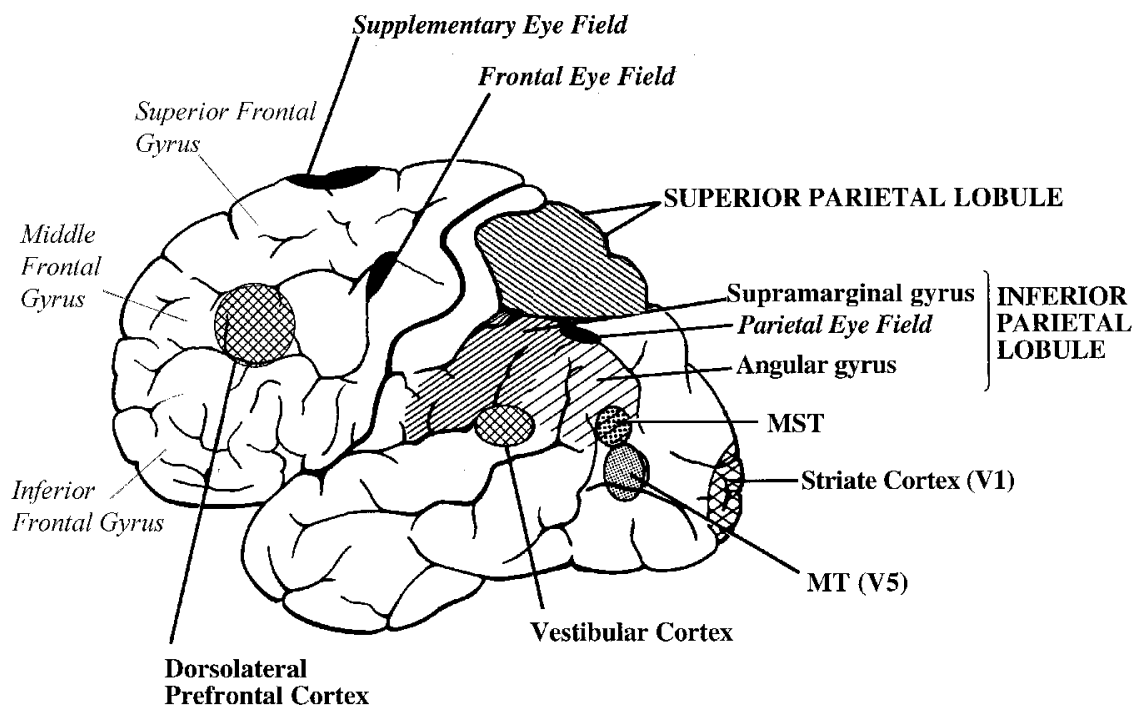




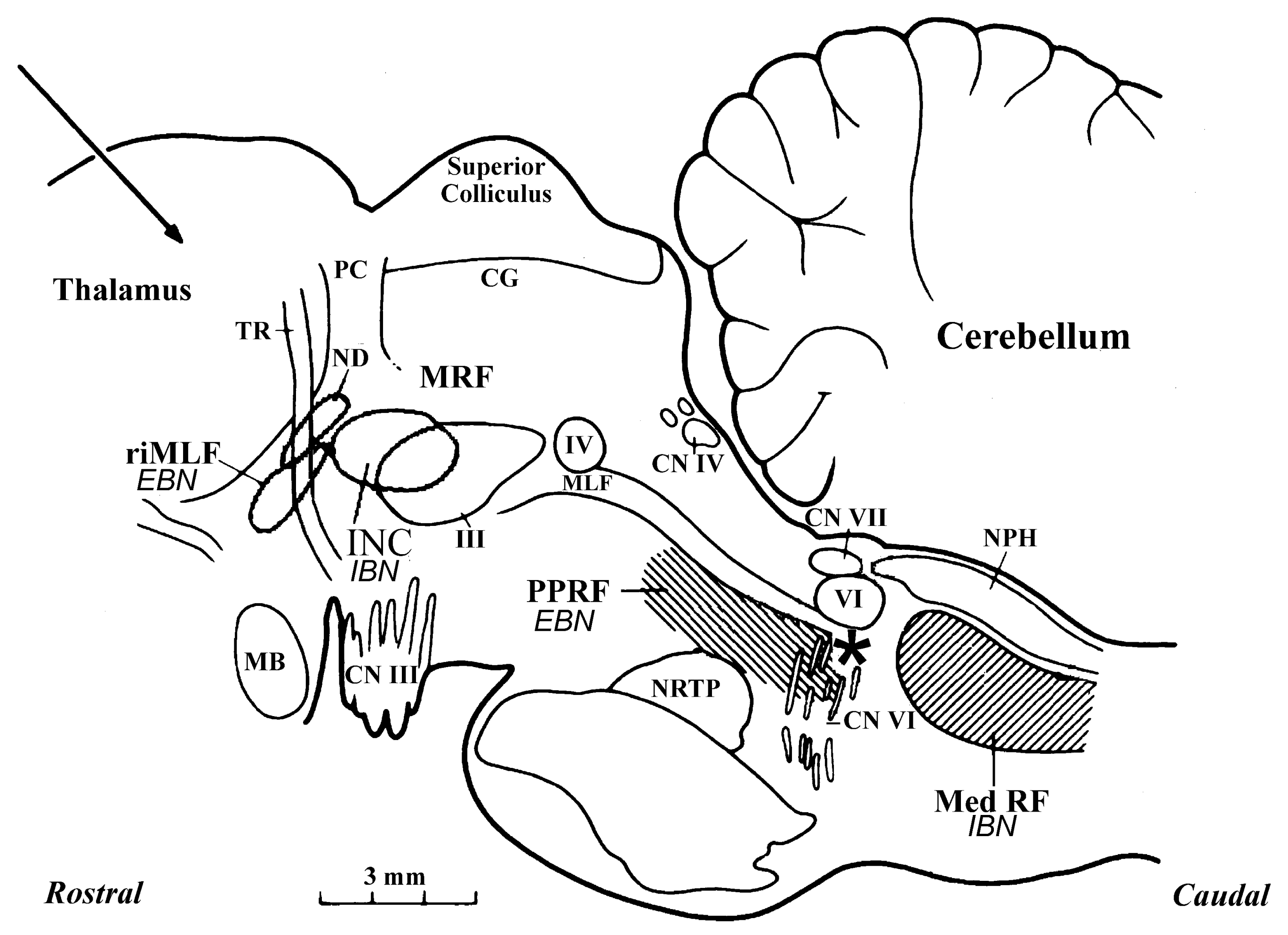


